Trinity University

Digital Commons @ Trinity

Biology Faculty Research

Biology Department

$10-2013$

\title{
Colorful Displays Signal Male Quality in a Tropical Anole Lizard
}

\author{
E. G. Cook
}

Troy G. Murphy

TrinityUniversity, tmurphy@trinity.edu

Michele A. Johnson

Trinity University, mjohnso9@trinity.edu

Follow this and additional works at: https://digitalcommons.trinity.edu/bio_faculty

Part of the Biology Commons

\section{Repository Citation}

Cook, E. G., Murphy T. G., Johnson M. A. (2013). Colorful displays signal male quality in a tropical anole lizard. Naturwissenschaften, 100(10), 993-996. doi:10.1007/s00114-013-1095-5

This Article is brought to you for free and open access by the Biology Department at Digital Commons @ Trinity. It has been accepted for inclusion in Biology Faculty Research by an authorized administrator of Digital Commons@ Trinity. For more information, please contact jcostanz@trinity.edu. 


\title{
Colorful displays signal male quality in a tropical anole lizard
}

\author{
Ellee G. Cook • Troy G. Murphy • Michele A. Johnson
}

Received: 4 July 2013 /Revised: 21 August 2013 / Accepted: 22 August 2013 /Published online: 1 September 2013

(C) Springer-Verlag Berlin Heidelberg 2013

\begin{abstract}
Parasites influence colorful ornaments and their behavioral display in many animal hosts. Because coloration and display behavior are often critical components of communication, variation in these traits may have important implications for individual fitness, yet it remains unclear whether such traits are signals of quality in many taxa. We investigated the association between ectoparasitic mite load and the color and behavioral use of the throat fan (dewlap) by male Anolis brevirostris lizards. We found that heavily parasitized lizards exhibited lower body condition, duller dewlaps, and less frequent dewlap displays than less parasitized individuals. Our results thus suggest that highly parasitized individuals invest less in both ornamental color and behavioral display of that color. Because the two components of the signal simultaneously provide information on male quality, this study provides novel support for the long-standing hypothesis that colorful traits may function as social or sexual signals in reptiles.
\end{abstract}

Keywords Anolis · Color · Dewlap · Display behavior . Ectoparasites

\section{Introduction}

Ectoparasites exploit a variety of host resources and can thus affect many aspects of host condition (Lehmann 1993). Colorful ornaments are often vulnerable targets of the negative effects of ectoparasites (Hamilton and Zuk 1982; Fitze and Richner 2002) because color expression is linked to physiological processes underlying condition (Hill et al. 2009).

Communicated by: Sven Thatje

E. G. Cook • T. G. Murphy • M. A. Johnson $(\bowtie)$

Department of Biology, Trinity University, San Antonio,

TX 78212, USA

e-mail:mjohnso9@trinity.edu
Ectoparasites have been found to limit color expression (Tschirren et al. 2003) and behavioral display (Doucet and Montgomerie 2003); however, the degree to which ectoparasites affect fitness remains unclear (Proctor and Owens 2000). Among taxa as diverse as insects, fish, birds, and reptiles, individuals use coloration to communicate quality and status (Bradbury and Vehrencamp 2011), yet we lack a general understanding of whether ectoparasites alter the information signaled by colorful animal structures.

Anolis lizards are an excellent group in which to investigate the potential for ectoparasites to influence the coloration and behavioral use of a color signal. Most anoles possess colorful dewlaps (throat fans) primarily extended during courtship and territory defense (Jenssen 1977). The dewlap is a signal of male fighting ability (Vanhooydonck et al. 2005), and its behavioral use is thought to influence mating success (Tokarz et al. 2005). However, the communication role of dewlap color is not clear (Nicholson et al. 2007) and it is unknown whether signal color and display behavior interact to indicate advertiser condition.

Parasites may negatively affect both physical ornament properties such as color and behavioral investment in ornament display. Color can be produced via structural mechanisms or by deposition of pigments such as carotenoids and pterins (Steffen and McGraw 2007; San-Jose et al. 2013), all of which influence anole skin coloration (Macedonia et al. 2000; Steffen and McGraw 2007). Many pigments also serve important physiological functions, including acting as free radical scavengers (McGraw 2005). Pigment allocation to ornaments thus reduces the availability of these bioactive pigments for use in mounting immune responses (McGraw and Ardia 2003). Only individuals with fewer parasites or increased ability to combat infestation should allocate sufficient pigment resources to produce high quality coloration (but see Steffen et al. 2010). Coloration may then signal the level of a host's parasite infestation or the preparedness of its 
immune system (Lozano 1994). Parasites also affect host metabolism (Booth et al. 1993) influencing the energy allocated to behavior. In many taxa, ectoparasites are negatively associated with display behavior, such that heavily parasitized individuals display less frequently than individuals with fewer parasites (e.g., Clayton 1990). The simultaneous effect of parasites on color and behavior generates the potential for information about individual quality to be directly communicated by both colors and behavioral advertisement of these colors.

Here, we investigated the relationship between ectoparasite load, dewlap coloration, and display behavior in male Anolis brevirostris, trunk-dwelling lizards that have yellow to redorange dewlaps. Lizards in our study population were naturally parasitized by ectoparasitic trombiculid mites in the folds of the dewlap and axillae. These body fluid-feeding mites may negatively affect hosts in a variety of ways, including inducing immune responses due to dermal inflammation and necrosis (Goldberg and Bursey 1991). We tested the hypothesis that dewlap color and display both signal male quality in $A$. brevirostris. Specifically, we predicted that heavily parasitized individuals exhibit less vibrantly colored dewlaps, lower body condition, and fewer dewlap displays than less parasitized individuals.

\section{Materials and methods}

We observed the behavior of 30 adult male $A$. brevirostris lizards at CoralSol Resort in Barahona, Dominican Republic in July 2011. We performed 30-60 $\mathrm{min}$ (mean=58.9 $\mathrm{min}$ ) observations for each lizard recording all display behaviors of the focal lizard. After observation, we captured each lizard and confirmed its sex by the presence of hemipenes (male copulatory organs). We measured each lizard's snout-vent length, mass, and the length of the second ceratobranchial cartilage, a linear proxy for dewlap size (Johnson and Wade 2010). Using a hand lens, we counted each lizard's ectoparasitic mites. Prior to dewlap color measurement, lizards were held in individual bags for $1-35 \mathrm{~h}$ (mean=7.61 h). Holding time was not statistically associated with any subsequent measure of dewlap coloration (results not shown).

We measured dewlap coloration for each lizard using an Ocean Optics 20001 spectrometer and PX-2 pulsed xenon lamp (Ocean Optics Inc., Dunedin FL). We used a fiber optic probe fitted with a plastic probe holder secured at a $90^{\circ}$ angle to light the sample and measure dewlap reflectance. The probe holder minimized ambient light in reflectance measures and maintained a consistent distance between the probe and dewlap. Reflectance was quantified as the proportion of light reflected from the dewlap at $1 \mathrm{~nm}$ increments within the lizard visible range (320-700 nm, Fleishman et al. 1997). Dewlap reflectance was measured relative to a Spectralon white reflectance standard (Lapsphere Inc., NH) with the system calibrated against this and a dark standard prior to measuring each individual. We took reflectance measurements at five haphazard locations within the central region of the dewlap, on the left, lateral side of the fully extended dewlap.

Using the mean reflectance curve for each individual, we calculated the following tristimulus variables with RCLR 9.33 (Montgomerie 2010): mean brightness (mean reflectance across 320-700 nm; herein "brightness"), hue (wavelength corresponding to [ $\{$ max reflectance - min reflectance $\} / 2])$, and red and yellow chroma (sum of reflectance from 605-700 and 325-550 nm, respectively, divided by brightness).

We used linear regressions to determine whether ectoparasite load predicted lizard body condition, tristimulus measures of dewlap color, or dewlap display rate and whether dewlap color was associated with dewlap display rate. To estimate body condition, we used standardized residuals from a linear regression with body length and mass (Jakob et al. 1996). One individual performed dewlap extensions at a rate greater than two standard deviations above the mean and was excluded. Except where noted, analyses with and without this individual were similar.
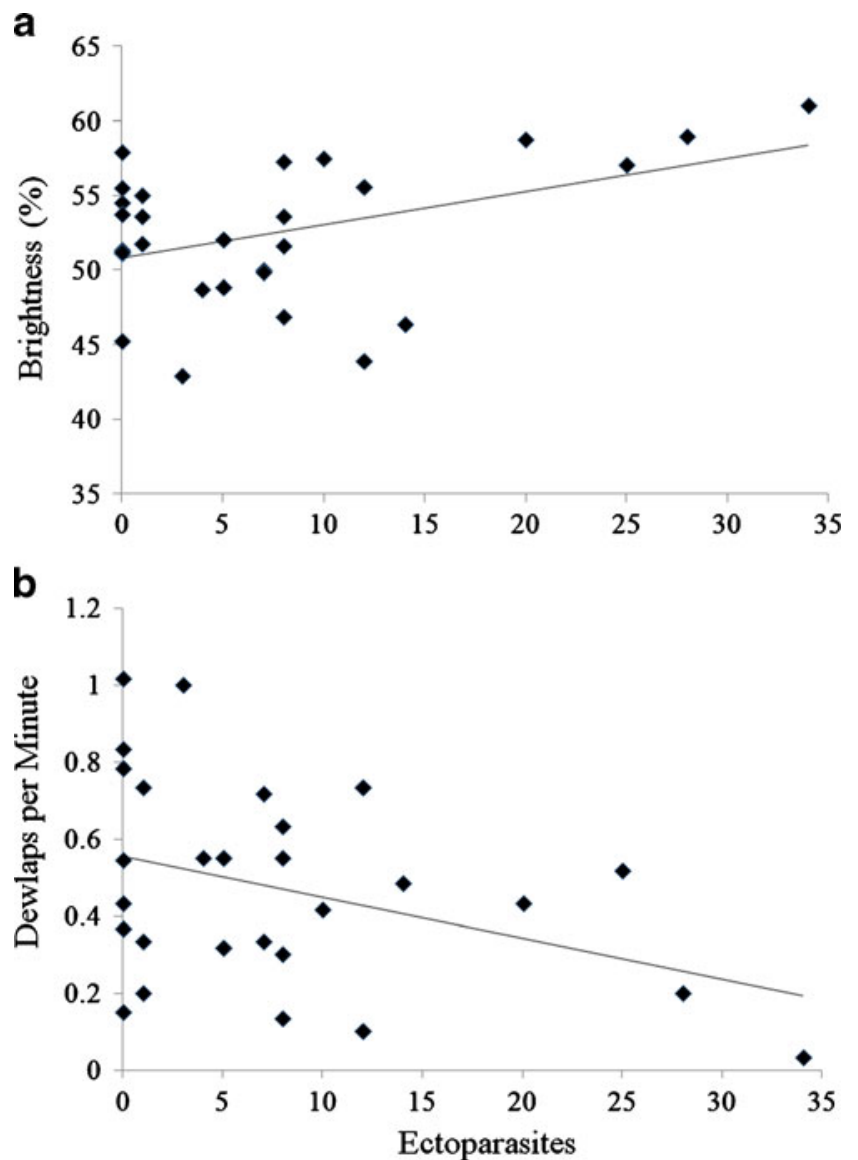

Fig. 1 Ectoparasite load predicts dewlap brightness and display rate. a Each individual's dewlap brightness represents the average brightness (mean reflectance between 320 and $700 \mathrm{~nm}$ ) calculated using five measurements of each dewlap. b Dewlap display rates represent dewlap extensions performed per minute of focal observation 


\section{Results}

Parasites and coloration

Twenty-two of the 30 males were parasitized by 1-34 trombiculid mites (mean $=7.93, \mathrm{SE}=1.68)$. Dewlap brightness increased with ectoparasite load $\left(\mathrm{F}_{1,27}=6.07, p=0.02, R^{2}=\right.$ 0.18 ; Fig. 1a), but parasite load was not associated with dewlap hue $\left(\mathrm{F}_{1,27}=1.72, p=0.20\right)$, red chroma $\left(\mathrm{F}_{1,27}=2.58, p=0.12\right)$, or yellow chroma $\left(\mathrm{F}_{1,27}=0.05, p=0.81\right)$.

Parasites and display behavior

Lizards with higher ectoparasite loads displayed their dewlaps less frequently than less parasitized lizards $\left(\mathrm{F}_{1,27}=4.38, p=\right.$ $0.046, R^{2}=0.14$, Fig. 1b; with outlier included, $\mathrm{F}_{1,28}=1.21$, $p=0.28$ ). More colorful (less bright) lizards performed more dewlap extensions than lizards with less colorful dewlaps $\left(\mathrm{F}_{1,27}=6.48, p=0.017, R^{2}=0.19\right.$; with outlier included, $\left.\mathrm{F}_{1,28}=1.06, p=0.31\right)$. Dewlap display rate was not associated with hue or chroma $(p>0.12)$.

\section{Parasites and condition}

Ectoparasite load was negatively associated with body condition $\left(\mathrm{F}_{1,27}=14.0, p=0.001, R^{2}=0.34\right)$, such that more parasitized lizards had lower condition, but body condition was not related to any measure of dewlap color (all tristimulus variables: $p>$ 0.22 ). Individuals with higher body condition displayed more frequently than lower condition individuals $\left(\mathrm{F}_{1,27}=10.5, p=\right.$ $0.003, R^{2}=0.28$; with outlier included, $\mathrm{F}_{1,28}=3.08, p=0.09$ ).

\section{Discussion}

This study demonstrates that dewlap coloration and display behavior may serve as honest indicators of male quality in lizards. Associations between the two components of dewlap display, ectoparasite load, and lizard condition indicate that coloration and behavior convey important information that may be interpreted by prospective mates and rivals, potentially affecting social interactions and reproductive success.

Our observation that heavily parasitized $A$. brevirostris have brighter dewlaps suggests that these hosts' dewlaps may have fewer light-absorbing pigments. Brightness is a measure of the light reflected of a surface, and pigments act in a subtractive manner by absorbing certain wavelengths. If highly parasitized individuals are depositing fewer pigments in dewlaps, this may indicate that they are allocating more pigment resources to immune function to combat parasitism (McGraw and Ardia 2003). However, alternative mechanisms could also account for the observed color differences. For example, pigment-based ornamental colors are often enhanced by underlying structural color components (Shawkey and Hill 2005) such as iridophores, and recent evidence suggests that color variability may be strongly influenced by differences in these underlying reflective surfaces rather than differences in pigment allocation alone (San-Jose et al. 2013).

Increased parasite loads were also associated with lower body condition and less frequent display behavior. Both of these relationships may result from mites reducing available host resources. This may occur as mites siphon resources by digesting host tissues, directly reducing the total resources available to the host, or infection by mites may stimulate a costly immune response drawing resources from other host metabolic processes (Bonneaud et al. 2003). Alternatively, low condition lizards may be more susceptible to parasite infection. Surprisingly, while both body condition and color were associated with parasitism, body condition itself was not associated with color, possibly indicating that coloration is more influenced by the direct effects of parasitism.

In many cases, the most valuable information about an animal's quality may be communicated by a combination of ornamental structures and the behaviors that display them (i.e., a multi-component signal; Johnstone 1995) rather than either trait alone. For example, female mate choice in guppies is influenced by both male coloration and display behavior such that the quality of these traits together determines mate choice (Kodric-Brown and Nicoletto 2001). This integration of information from the color of ornamental structures and their display also has the potential to influence social or sexual selection in reptiles. Future studies that manipulate anole parasite loads and measure changes in dewlap color and use would experimentally verify these results.

Acknowledgments We thank T. Sanger, N. Jacewitz, and D. Castro for field assistance; the staff of Coralsol for logistical support; Trinity University's Department of Biology, HHMI Summer Research Program, and the Arnold and Mable Beckman Foundation for financial support.

\section{References}

Bonneaud C, Mazuc J, Gonzalez G, Haussy C, Chastel O, Faivre B, Sorci $\mathrm{G}$ (2003) Assessing the cost of mounting an immune response. Am Nat 161:367-379

Booth DT, Clayton DH, Block BA (1993) Experimental demonstration of the energetic cost of parasitism in free-ranging hosts. Proc R Soc Lond B 253:125-129

Bradbury JW, Vehrencamp SL (2011) Principles of Animal Communication, 2nd edn. Sinauer, Sunderland

Clayton DH (1990) Mate choice in experimentally parasitized rock doves: lousy males lose. Am Zool 30:251-262

Doucet SM, Montgomerie R (2003) Multiple sexual ornaments in satin bowerbirds: ultraviolet plumage and bowers signal different aspects of male quality. Behav Ecol 14:503-509

Fitze PS, Richner H (2002) Differential effects of a parasite on ornamental structures based on melanins and carotenoids. Behav Ecol 13:401-407 
Fleishman L, Bowman M, Saunders D, Miller W, Rury M, Loew E (1997) The visual ecology of Puerto Rican anoline lizards: habitat light and spectral sensitivity. J Comp Physiol A 181: 446-460

Goldberg SR, Bursey CR (1991) Integumental lesions caused by ectoparasites in a wild population of the side-blotched lizard (Uta stansburiana). J Wildl Dis 27:68-73

Hamilton WD, Zuk M (1982) Heritable true fitness and bright birds: a role for parasites? Science 218:384-387

Hill GE, Hood WR, Huggins K (2009) A multifactorial test of the effects of carotenoid access, food intake and parasite load on the production of ornamental feathers and bill coloration in American goldfinches. J Exp Biol 212:1225-1233

Jakob EM, Marshall SD, Uetz GW (1996) Estimating fitness: a comparison of body condition indices. Oikos 77:61-67

Jenssen TA (1977) Evolution of anoline lizard display behavior. Am Zool 17:203-215

Johnson MA, Wade J (2010) Behavioural display systems across nine Anolis lizard species: sexual dimorphisms in structure and function. Proc R Soc Lond B 277:1711-1719

Johnstone RA (1995) Honest advertisement of multiple qualities using multiple signals. J Theor Biol 177:87-94

Kodric-Brown A, Nicoletto PF (2001) Female choice in the guppy (Poecilia reticulata): the interaction between male color and display. Behav Ecol Sociobiol 50:346-351

Lehmann T (1993) Ectoparasites: direct impact on host fitness. Parasitol Today 9:8-13

Lozano GA (1994) Carotenoids, parasites, and sexual selection. Oikos 70:309-311

Macedonia JM, James S, Wittle LW, Clark DL (2000) Skin pigments and coloration in the Jamaican radiation of Anolis lizards. J Herpetol 34: 99-109
McGraw KJ (2005) The antioxidant function of many animal pigments: are there consistent health benefits of sexually selected colourants? Anim Behav 69:757-764

McGraw KJ, Ardia DR (2003) Carotenoids, immunocompetence, and the information content of sexual colors: an experimental test. Am Nat $162: 704-712$

Montgomerie R (2010) RCLR, version 9.33. Kingston (Canada): Queen's University. Available from: http://post.queensu.ca/ mont/color/. Accessed 1 Jul 2012

Nicholson KE, Harmon LJ, Losos JB (2007) Evolution of Anolis lizard dewlap diversity. PLoS One 2:e274

Proctor H, Owens I (2000) Mites and birds: diversity, parasitism and coevolution. Trends Ecol Evol 15:358-364

San-Jose LM, Granado-Lorencio F, Sinervo B, Fitze PS (2013) Iridophores and not carotenoids account for chromatic variation of carotenoid-based coloration in common lizards (Lacerta vivipara). Am Nat 181:396-409

Shawkey MD, Hill GE (2005) Carotenoids need structural colours to shine. Biol Lett 1:121-124

Steffen JE, McGraw KJ (2007) Contributions of pterin and carotenoid pigments to dewlap coloration in two anole species. Comp Biochem Phys B 146:42-46

Steffen JE, Hill GE, Guyer C (2010) Carotenoid access, nutritional stress, and the dewlap color of male brown anoles. Copeia 2010:239-246

Tokarz RR, Paterson AV, McMann S (2005) Importance of dewlap display in male mating success in free-ranging brown anoles (Anolis sagrei). J Herpetol 39:174-177

Tschirren B, Fitze PS, Richner H (2003) Proximate mechanisms of variation in the carotenoid- based plumage coloration of nestling great tits (Parus major L.). J Evol Biol 16:91-100

Vanhooydonck B, Herrel A, van Damme R, Irschick D (2005) Does dewlap size predict male bite performance in Jamaican Anolis lizards? Funct Ecol 19:38-42 